GOVERNANÇA CORPORATIVA E OS DETERMINANTES DA ESTRUTURA DE CAPITAL EM EMPRESAS BRASILEIRAS

\title{
CORPORATE GOVERNANCE AND THE DETERMINANTS OF CAPITAL
} STRUCTURE IN BRAZILIAN COMPANIES

Daniel Dayrell Matragrano UNIBH e Faculdade Milton Campos danieldm@globo.com.br

Patrícia Bernardes PPGA-PUC Minas patriciabernardes@ pucminas.br

Carlos Alberto Gonçalves Universidade FUMEC - MG carlos@face.ufmg.br

Submissão: $25 / 01 / 2015$ Aprovação: 11/11/2015 


\section{RESUMO}

Este artigo trata da relação entre governança corporativa e estrutura de capital das empresas brasileiras. O pressuposto é que a adoção de boas práticas de governança corporativa pode influenciar a formação das fontes de financiamento das empresas e de seus atributos determinantes. O objetivo geral foi identificar se as empresas que aderiram ao segmento do Novo Mercado apresentaram diferenças significativas em sua estrutura de capital e em seus atributos com relação às empresas listadas no Mercado Tradicional, para os anos de 2010 e 2013. A metodologia do trabalho é de natureza quantitativa. Utilizou-se de dados secundários obtidos na BM\&F Bovespa e de técnicas de regressão linear múltipla e análise de coeficientes de correlação. A apresentação e análise de resultados do trabalho demonstrou a presença de diferenças estatísticas significativas entre os atributos determinantes da estrutura de capital das empresas, evidenciando a influência positiva das empresas que adotam as boas práticas de governança corporativa. Os avanços nesta área de estudo podem ser obtidos pela incorporação de um maior número de variáveis que influenciam a estrutura de capital, bem como a ampliação dos períodos para o levantamento de dados.

Palavras Chave: Governança corporativa; Estrutura de capital; Novo Mercado. 


\begin{abstract}
This dissertation deals with the relationship between corporate governance and capital structure of Brazilian companies. The assumption is that the adoption of good corporate governance practices can influence the formation of the sources of business financing and its determinants attributes. The general objective was to identify whether the companies adhering to the Novo Mercado segment showed significant differences in their capital structure and its attributes with respect to the listed companies in traditional segments, for the years 2010 and 2013. The methodology of this study was quantitative. It was used of secondary data obtained from BM \& F Bovespa, and mathematical, statistical and econometric techniques. The presentation and analysis of results of the work showed the presence of differences between the determinants attributes of the capital structure, showing the positive influence of companies that adopt good corporate governance practices. Advances in this area of study can be obtained by incorporating a greater number of variables that influence the capital structure as well as the extension of periods for data collection.
\end{abstract}

Key Words: Corporate Governance, Capital Structure, Novo Mercado. 


\section{INTRODUÇÃO}

A governança corporativa (GC) está fundamentada em princípios como equidade, transparência de informações, prestação de contas e conformidade no cumprimento de normas reguladoras (Andrade, Rosseti, 2012). A implementação destas práticas busca mitigar as assimetrias tanto do ponto vista de direitos dos stakeholders (diretos, indiretos), quanto do ponto de vista informacional, criando melhores condições para a redução do conflito de interesses (Silveira, 2008). Os stakeholders diretos (acionistas, funcionários, terceirizados, fornecedores, clientes) apresentam maior interesse no acompanhamento das informações sobre as firmas e os efeitos que produzem nos ambientes externo de mercado, economia e sociedade.

A literatura identifica e aponta quatro principais abordagens de governança, enfoque financeiro, ponto de vista dos públicos relevantes (stakeholders), abordagem político e de procuradoria.

Este trabalho optou por destacar o modelo financeiro de Governança Corporativa - GC que prioriza as decisões no sentido de maximizar o retorno sobre os investimentos financeiros realizados pelos acionistas. Os princípios de governança, como equidade, transparência de informações, prestação de contas e conformidade no cumprimento de normas reguladoras, contribuem para a redução de riscos das corporações.

A redução do risco econômico, associado às decisões de investimento, e também do risco financeiro, decorrente de decisões de gestão de caixa e do endividamento, propiciam a maior atratividade de fontes de financiamento externas (Assaf Neto, 2012).

Conforme dados da BM\&F Bovespa (2015), o mercado de capitais brasileiro oferece três níveis diferenciados de GC. Além de cumprir a Lei das Sociedades Anônimas, as empresas participantes dos níveis N1, N2 ou do Novo Mercado celebram um contrato privado com a BM\&F Bovespa, no qual se comprometem a seguir várias exigências e também com a previsão das penalidades em caso de não cumprimento do contrato. O Novo Mercado, conta com 134 empresas participantes, de acordo com consulta realizada junto à BM\&F Bovespa (2015), e representa o nível de governança mais avançado no Brasil, no qual é esperado um elevado nível de respeito aos investidores, tratando com equilíbrio os acionistas controladores e os minoritários. Exemplos desta conduta de maior deferência aos investidores é a estrita emissão de ações com direito a voto e também com direito ao tag along de 100\%, em caso de oferta de compra de ações do bloco controlador. 
O Novo Mercado representa atualmente a principal escolha para as empresas que desejam abrir o seu capital na BM\&F Bovespa. Os níveis de Governança 1 e 2, que contam, respectivamente com 30 e 20 empresas (BM\&F Bovespa, 2015), têm atendido principalmente as empresas que eram listadas anteriormente no segmento tradicional, que não pressupõe a adoção das práticas de governança corporativa.

Diante do exposto, este artigo se propõe a responder a seguinte pergunta: existe diferença significativa entre empresas do Novo Mercado e empresas do Mercado Tradicional da BM\&F Bovespa no que se refere à estrutura de capital e os seus atributos?

Como pressuposto considera-se que a governança corporativa atua na redução do nível de assimetria de informação entre organizações e os investidores e poderia influenciar na formação da estrutura de capital das empresas.

Este estudo busca contribuir para o entendimento das influências das melhores práticas de governança corporativa no Novo Mercado - NM, e as suas consequencias, no que se refere à obtenção de recursos financeiros nos mercados de capitais, para a promoção do crescimento, em relação às outras empresas de sociedades anônimas de capital aberto (empresas tradicionais).

Espera-se que empresas que contam com boas práticas de governança corporativa tenham maior participação do financiamento por intermédio do mercado de capitais, inclusive às taxas de juros menores, em relação às empresas tradicionais que não aderiram aos segmentos diferenciados de governança.

Este artigo busca analisar se as empresas dotadas de melhores práticas de governança apresentam diferenças na composição de seu capital. A suposição é de que as melhores práticas de GC alteram a estrutura de capital. Os princípios equidade, transparência, prestação de contas responsáveis, perenidade da empresa atuam no sentido de minimizar assimetrias entre a empresa e os investidores, contribuindo para a mitigação de riscos financeiros.

Assim, o objetivo geral do trabalho é o de identificar se as empresas que aderiram ao segmento do Novo Mercado apresentaram diferenças significativas em sua estrutura de capital e em seus atributos com relação às empresas listadas no segmento tradicional, para os anos de 2010 e 2013. Este período foi escolhido por ser recente e pelo fato de não terem sido identificados trabalhos que buscaram compreender a estrutura de capital e a relação com a governança para nestes anos, além de excluir os principais anos da última crise internacional, 2008 e 2009. 
Como objetivos específicos, busca-se analisar as informações contábeis e financeiras publicadas por empresas que fazem parte do segmento de governança da BM\&F Bovespa conhecida como Novo Mercado e compará-las, com a utilização de índices de estrutura de capital, com empresas presentes no segmento tradicional.

$\mathrm{Na}$ sequência, as empresas são analisadas com relação aos atributos que podem apresentar um grau de influência para a determinação da sua estrutura de capital, dentre eles, tamanho da empresa, rentabilidade, estrutura de propriedade.

\section{FUNDAMENTAÇÃO TEÓRICA}

De acordo com Berle e Means (1932), o crescimento e o fortalecimento de grandes corporações fomentou a prática da divisão entre propriedade e controle das grandes corporações. A separação entre a propriedade e o controle representa uma das bases conceituais da governança corporativa. A Teoria de Agência, desenvolvida por Jensen e Meckling (1976), com base em Berle e Means (1932), tem uma grande importância para os estudos e para a prática de governança corporativa. Esta teoria considera a existência da assimetria de informações entre os agentes e também com o direito de propriedade e os contratos.

\subsection{Origem da Governança e os Conflitos decorrentes da separação entre a Propriedade e a Gestão}

Um relacionamento de agência pode ser definido como um contrato no qual um ou mais agentes (Agente) e um ou mais acionistas (Principal) realizam ações de seus interesses. Para conduzir o dia à dia dos negócios, o Principal delega ao Agente o poder para tomar decisões e fazer a gestão da firma. Se ambas as partes, Agente e Principal, agirem no sentido de maximizarem os seus interesses individuais, existem boas razões para pressupor o surgimento e a existência de conflitos, pois o Agente nem sempre agirá no sentido dos maiores interesses do Principal. O principal pode limitar as divergências com o agente mediante adoção de mecanismos de controle e incentivos para o monitoramento das ações do agente, no entanto, incorre em custos para a realização destas ações, que buscam assegurar maior nível de correspondência aos interesses dos proprietários. Estes custos positivos para a realização do monitoramento das ações do agente recebem o nome de custos de agência e 
estão associados à esta necessidade de promover incentivos para que os agentes cumpram as suas responsabilidades que foram delegadas pelo principal, agindo no melhor sentido para o alcance dos interesses do principal. De acordo com Jensen e Meckling (1976), os custos diretos de agência serão o somatório de: (i) custos de monitoramento do principal, (ii) os gastos incorridos dos agentes para atendimento dos interesses do principal e (iii) a perda residual da organização decorrente da existência destes custos.

Segundo Jensen e Meckling (1976), na presença de elevados custos diretos de agência decorrentes da relação entre o acionista controlador e agente, podem motivar os investidores a descontá-los dos preços das ações no momento que a empresa busque novos recursos no mercado, reduzindo o valor da firma. As ações destas empresas serão subavaliadas devido à percepção de maiores riscos para a realização do investimento e à existência de conflitos inerentes à relação entre o agente e o principal. A elevação dos custos de captação se manifesta para a empresa participante do mercado acionário, ocorrendo uma transferência dos custos de agência para o caixa da firma.

\subsection{Governança Corporativa: Conceitos, Valores e Principais Modelos}

O conceito de governança, segundo Alves (2001), tem como ponto de partida a busca do aperfeiçoamento do comportamento das pessoas e instituições. A adesão à governança deve inibir comportamentos oportunistas da empresa e de seus administradores, passando a adotar comportamentos socialmente responsáveis e sustentáveis ao longo prazo.

A GC lida com diversos stakeholders, pessoas, grupos ou instituições com interesses legítimos nas empresas, como, por exemplo: os proprietários, investidores, diretoria executiva, conselho de administração, conselho fiscal, auditoria independente, empregados, credores, fornecedores, clientes, consumidores, comunidades locais, a sociedade, governos e ONGs. A governança busca viabilizar o equilíbrio de múltiplos interesses, indo além da visão estritamente financeira voltada para a maximização de lucros.

A Governança Corporativa está baseada em valores que lhe dão sustentação, que conectam concepções, práticas e processos da alta gestão. Segundo Andrade e Rosseti (2012), os quatro valores fundamentais da Governança Corporativa são: Fairness, Disclosure, Accountability e Compliance. Fairness significa senso de justiça, equidade no tratamento das partes interessadas, principalmente os acionistas majoritários e minoritários. Disclosure pode ser entendido como a transparência, principalmente aquelas que impactam os negócios e 
envolvem resultados, riscos e oportunidades. Accountability é a prestação responsável de contas, apoiada pelas melhores práticas contábeis e de auditoria. Compliance significa a conformidade no cumprimento de normas reguladoras baseadas nos estatutos sociais, em regimentos internos e nas instituições legais do país.

A lógica financeira da governança corporativa, de acordo com Andrade e Rosseti (2012), pode ser definida, como a perspectiva das empresas de geração de lucros e retorno aos proprietários que investiram na integralização do capital. A GC pode mitigar os conflitos existentes nas organizações, elevando o potencial de geração de lucros da empresa. Neste sentido, a adoção de mecanismos eficientes de governança proporciona a redução da assimetria de informação entre agentes internos e externos.

\subsection{A Governança Corporativa no Brasil e o Mercado de Capitais: o momento atual}

A Governança Corporativa no Brasil encontra-se em um estágio de aperfeiçoamento e desenvolvimento de suas práticas. Segundo Peixoto (2012), os motivos principais são: mercado de capitais ainda pouco expressivo, propriedade acionária concentrada, sobreposição propriedade-gestão, conflito de agência entre acionistas majoritários e minoritários, fraca proteção aos minoritários, enforcement deficiente e a baixa eficácia dos conselhos de administração.

De acordo com Andrade e Rosseti (2012), existem sinais de evolução das boas práticas de governança corporativa no Brasil devido às fusões, entrada de investimentos estrangeiros, restruturações societárias em empresas de capital aberto, crescente profissionalização dos Conselhos de Administração, aumentos das ofertas públicas de ações e maior conscientização da classe empresarial.

O desenvolvimento das práticas de GC no Brasil, via mercado de capitais, passa pela criação de níveis diferenciados de governança corporativa, dentre eles o Novo Mercado.

\subsection{Governança Financeira}

O trabalho pioneiro de Jensen e Meckling (1976) pode ser considerado um marco para a discussão das práticas de Governança Corporativa. As corporações necessitam de recursos financeiros, que podem ser obtidos por meio de endividamento e venda de ações para investirem, crescerem e desenvolverem as suas atividades. Segundo os autores, ao incorporem mais capital de fontes externas à organização, surgirão conflitos de agência, entre os 
administradores proprietários e os novos acionistas, ou entre aqueles e os credores. Estes conflitos ocorrem em qualquer relação no qual o principal delega aos agentes autoridade para a tomada de decisões, em seu interesse.

A discussão dos conflitos parte dos trabalhos de Coase (1937) e Alchian e Demsetz (1972) que consideram as firmas estruturas constituídas por vários contratos. Existindo contratos, eles serão imperfeitos e sujeitos aos conflitos entre as partes interessadas. A minimização dos conflitos é possível, porém apenas com a ocorrência de custos, chamados de custos de agência. Os proprietários adotarão mecanismos de monitoramento com o objetivo de reduzir o comportamento inadequado dos gestores que busquem maximizar seus privilégios não pecuniários, decorrentes da posição em que ocupam na organização.

\subsubsection{A Abordagem Clássica de Jensen e Meckling}

A decisão por obtenção de financiamento para a firma no mercado aberto se direciona para três principais alternativas, segundo Jensen e Meckling (1976). É possível obter recursos financeiros: (i) por intermédio dos acionistas internos, aqueles que fazem parte do atual capital da organização, aumentando o capital próprio com recursos dos proprietários; (ii) com a venda de ações que estão no caixa da firma ou lançamento de novas ações para investidores, que serão tratados como acionistas externos e, (iii) pela obtenção de capital de fontes de financiamento externas do mercado (bancos, fundos de private equity, dentre outros), ou seja, por contratação de endividamento.

A decisão entre utilizar capital externo, capital interno ou endividamento depende dos benefícios advindos de cada uma destas opções. Um empresário não pode utilizar de apenas uma forma de endividamento para constituir as suas fontes de financiamento. Esta situação reduzirá a sua flexibilidade de operação financeira e pode aumentar as exigências dos credores, em comportamento oportunista, aumentando os riscos em caso de busca de novos investimentos. O aumento do endividamento pode trazer consigo vantagens pelos descontos decorrentes dos subsídios tributários que reduzam o custo deste capital, tornando interessante a sua adoção (alavancagem) por parte da organização. Outro aspecto é o aproveitamento de oportunidades de investimento via contratação de financiamentos, criando situações oportunas para maximizar o capital investido. 
O capital interno isoladamente limita as possibilidades de crescimento da organização, tornando-a incapaz de crescer a taxas mais elevadas. Por outro lado, os conflitos de agência, entre majoritários e minoritários e os custos de emissão de ações são eliminados.

O capital externo, apesar das questões levantadas anteriormente, representa uma via de crescimento significativa. As corporações se desenvolveram muito nos últimos anos, apesar do potencial conflitos entre os acionistas. A existência de um ambiente institucional com regras claras e bem definidas, legislação adequada e contratos sofisticados contribuem com a redução do custo de agência.

\subsubsection{A Estrutura de Propriedade}

A estrutura de propriedade pode ser estabelecida em duas dimensões: a concentração da propriedade e a identidade do acionista majoritário. A concentração da propriedade se refere ao número de ações detidas por um acionista ou grupo de acionistas e a identidade do acionista majoritário está relacionada à qual categoria que mantém o controle da maior parte das ações da empresa, podendo ser representada por família, governo, banco, investidores institucionais. A concentração da propriedade está relacionada ao poder existente para influenciar os administradores, o nível de concentração de propriedade influencia para mais, ou para menos o poder dos administradores (Campos, 2006).

A identidade do proprietário poderá exercer influências sobre os objetivos organizacionais e a forma pela qual a empresa estabelece a sua estratégia, em questões como lucros, dividendos, estrutura de capital e taxas de crescimento (Campos, 2006).

A concentração de propriedade e a qualidade da proteção legal ao investidor estão relacionadas, de acordo com La Porta et al (1998). Em países com maior proteção legal ao investidor minoritário irão predominar estruturas pulverizadas e em outros que tenham menor proteção as estruturas concentradas serão as predominantes.

\subsubsection{Atributos Definidores da Estrutura de Capital}

A GC, os seus objetivos e os seus valores, podem exercer influência na definição da estrutura de capital das empresas. Segundo Silveira, Perobelli e Barros (2008), existe uma significativa influência, com sentido positivo, das práticas de GC sobre a alavancagem financeira, em particular das dimensões de governança relacionadas à estrutura de 
propriedade, por meio do nível de concentração do controle acionário, e a composição do conselho de administração. Segundo Assaf Neto (2010), as decisões de financiamento objetivam a melhor oferta de recursos e a melhor proporção a ser mantida entre o capital próprio e o de terceiros, considerando objetivos como a formação de sua estrutura de capital com custos reduzidos em relação à sua expectativa de retorno das aplicações

Considerando a extensa literatura que trata dos modelos de estrutura de capital, autores como Harris e Raviv (1991) e Myers (2002) construíram amplos panoramas destes campos de estudo e suas diversas subdivisões. De acordo com Myers (2002), estas teorias podem ser resumidas em quatro linhas principais: (i) a teoria de Modigliani-Miller que trata da irrelevância da estrutura de capital da empresas em que o valor das empresas e as decisões de investimentos não são afetadas pela estrutura de capital; (ii) a teoria de trade-off no qual as empresas realizam um balanceamento entre as vantagens tributárias do endividamento e o custo do desgaste com credores; (iii) a teoria de agência, no qual o financiamento corresponde aos incentivos pessoais dos executivos; (iv) a teoria pecking order, na qual o financiamento se adapta para mitigar os problemas causados pela assimetria de informações.

A determinação da estrutura de capital, a escolha entre a proporção de capital proveniente de dívidas ou de ações, pode ser influenciada por alguns atributos, de acordo com Titman e Wessels (1998). Estes atributos foram originados de várias teorias que sugerem o que pode afetar a escolha entre a utilização de dívidas ou de ações. São eles: a estrutura de ativos da empresa, os incentivos tributários para a utilização do capital proveniente de dívidas, crescimento, singularidade, a classificação da indústria, o tamanho da empresa, a volatilidade dos resultados e a rentabilidade.

Os tipos de ativos da empresa, tangíveis ou intangíveis, podem exercer influência na escolha do tipo de financiamento adotado, fazendo com que empresas com mais ativos tangíveis optem preferencialmente por dívidas e aquelas com ativos intangíveis busquem preferencialmente o capital próprio para a sua estrutura. Os incentivos tributários, quanto maiores forem, maior será a utilização do capital de terceiros, ao invés do capital próprio. O crescimento das empresas pode influenciar na maior presença do endividamento, notadamente o de curto prazo. A singularidade da organização pode reduzir o acesso ao endividamento, ao poder oferecer menos garantias para os credores. O mesmo ocorre para indústrias que precisam de serviços especializados para desenvolverem as suas atividades.

Perobelli e Famá (2002) basearam o seu artigo em Titman e Wessels (1998) e o adaptaram à realidade brasileira. Ainda de acordo com Titman e Wessels (1998), o tamanho 
da empresa afeta positivamente a sua capacidade de atrair capitais provenientes de dívidas e também de ações. A volatilidade dos ganhos das empresas pode afetar a disposição de fornecedores externos de capital, diminuindo a capacidade da organização de obter crédito proveniente de endividamento. A rentabilidade possui uma relação inversa com o endividamento das empresas, pois quanto mais rentável a empresa, maior a sua capacidade de gerar recursos provenientes das suas operações para ser utilizado como reserva para investimentos.

Alguns estudos, baseados em atributos que podem influenciar a estrutura de capital das empresas, foram desenvolvidos no Brasil, dentre eles Perobelli e Famá (2002). Este estudo selecionou 172 empresas de capital aberto no Brasil, realizando uma pesquisa com 165 empresas, pois algumas não poderiam fazer parte, pois apresentaram patrimônio líquido negativo no período de 1995 à 2000. Os atributos relacionados, que poderiam ser capazes de influenciar as decisões da estrutura de capital, foram o crescimento, a singularidade, outros benefícios fiscais, colaterais, o tamanho, a lucratividade, a volatilidade e a classificação da indústria.

Os resultados encontrados demonstraram uma relação negativa entre o grau de endividamento no curto prazo e atributo tamanho, indicando que empresas menores no Brasil são mais propensas ao endividamento de curto prazo, provavelmente devidos às dificuldades existentes no Brasil de captação de recursos de longo prazo. O fator crescimento dos ativos também foi negativamente relacionado com o grau de endividamento de curto prazo, demonstrando que empresas nesta situação tendem a utilizar menos o financiamento de curto prazo, buscando alternativas melhores para se financiar, com prazos mais longos e menor custo.

Um terceiro fator também apresentou relação com o endividamento de curto prazo, foi a lucratividade, decorrente do alto giro. Nesta situação, a relação identificada foi que o aumento da lucratividade provoca a presença de menor endividamento de curto prazo, demonstrando que as empresas podem utilizar fontes internas de recursos em detrimento de fontes externas providas por endividamento. Os demais atributos do estudo, singularidade, benefícios fiscais, colaterais, volatilidade e a classificação da indústria, não demonstraram uma relação com a estrutura de capital das empresas. Outro aspecto importante é que não foi identificado nenhuma relação entre todos os atributos citados e o endividamento de longo prazo das empresas participantes do estudo (Perobelli e Famá, 2002). 
Silveira, Perobelli e Barros (2008) pesquisaram 154 empresas não financeiras, pertencentes a 17 diferentes setores de atividade. A governança corporativa, incluída dentre os atributos que podem influenciar a estrutura de capital, foi medida através de um índice criado pelos autores que é composto por questões que tratam das dimensões de transparência (acesso às informações e conteúdo das informações) e da dimensão de estrutura de propriedade e conselho.

As empresas com a sua GC mais bem avaliadas de acordo com o índice IGOV, desenvolvido por Silveira (2004), ficam com uma pontuação superior às demais. Os resultados encontrados evidenciam que uma melhor pontuação no índice IGOV associam-se à um maior endividamento relativo. Anteriormente, Procianoy e Schnorrenberger (2004), chegaram a conclusão, a partir de dados levantados no mercado brasileiro, que o acúmulo de direitos de votos nas mãos dos maiores acionistas da empresa é inversamente proporcional ao seu grau de endividamento. Outra relação identificada no trabalho de Silveira, Perobelli e Barros (2008) é o relacionamento negativo existente entre a alavancagem, o grau de endividamento, e o fator rentabilidade. Esta constatação é compatível com a teoria da pecking order, demonstrando uma preferência pelo financiamento promovido por fontes internas de recursos da empresa

\section{MÉTODO APLICADO}

O levantamento de dados para esta pesquisa ocorreu por meio de uma investigação documental, com acesso aos relatórios de empresas representados por balanços e páginas na internet das companhias.

O estudo foi constituído por duas etapas de testes estatísticos. A primeira etapa buscou conhecer se empresas de dois segmentos distintos, Segmento Tradicional e Novo Mercado, da bolsa de valores do Brasil, a BM\&F Bovespa, apresentaram diferenças significativas em sua estrutura de capital e seus atributos, para os períodos analisado, ano de 2010 e 2013 . A escolha destes dois anos para este estudo ocorreu por não se ter conhecimento de pesquisa recente que investiga os atributos que influenciam a estrutura de capital corporativa no Brasil. Além disto, os períodos investigados não envolverem o período de crise econômica e financeira internacional. 
A segunda etapa utilizou a técnica estatística de análise de regressão múltipla para investigar qual a relação da estrutura de capital com os seus determinantes, dentre eles o tamanho da empresa, a rentabilidade e a estrutura de propriedade.

Este estudo foi desenvolvido com a utilização do software estatístico Minitab, amplamente utilizado no meio acadêmico para a realização de análises de dados

\subsection{Objetivos e unidade de análise}

Este trabalho buscou identificar se as empresas que aderiram ao segmento do Novo Mercado (NM) apresentaram diferenças significativas em sua estrutura de capital e de seus atributos com relação às empresas listadas no segmento tradicional para os anos de 2010 e de 2013 e também quais atributos que tem uma relação estatisticamente significante com a determinação da estrutura de capital das empresas brasileiras pesquisadas.

A amostragem da pesquisa, que diz respeito ao número de empresas que fizeram parte do estudo, foi de 50 empresas do Novo Mercado e 50 empresas da listagem geral da BM\&F Bovespa. Este número foi definido porque algumas empresas precisaram ser excluídas deste trabalho por não apresentarem dados em 2010 e 2013 devido ao ingresso recente no mercado de capitais, outras apresentaram inexistência de endividamento em algum dos períodos estudados, as empresas públicas e do segmento financeiro foram excluídas.

Buscou-se, a partir desta seleção da amostra, que contém empresas com práticas institucionalizadas de governança corporativa e empresas que não se comprometeram com estas práticas perante o mercado de capitais brasileiro, comparar dois grupos distintos de empresas, listadas em dois segmentos da bolsa de valores brasileira.

O critério para a seleção da amostra foi não probabilístico, ou seja, as empresas foram escolhidas intencionalmente pelo pesquisador. Para esta escolha foi considerado principalmente a disponibilidade e a facilidade de acesso às informações pretendidas. Foram excluídos da amostra o setor financeiro e as empresas de capital público ou misto. A exclusão destas empresas é justificada pela presença de características próprias que distorcem a avaliação delas na comparação com as demais selecionadas. 


\subsection{Processo de coleta e análise dos dados}

As duas listagens de empresas selecionadas, empresas do Novo Mercado e empresas do Segmento Tradicional, tratam-se de amostras independentes, que não possuem uma relação direta e não exercem influências uma na outra, ou seja, a decisão de estrutura de capital de empresas de governança não exerce influência na determinação da estrutura de capital das empresas do segmento tradicional. Este estudo não teve como objetivo comparar a estrutura de capital e os seus determinantes em 2010 e 2013 das mesmas empresas, mas sim uma comparação entre dois grupos de empresas de segmentos distintos nos dois anos da pesquisa.

Inicialmente todos os dados foram organizados em planilhas eletrônicas, momento que houve uma triagem das informações, confirmando se todas as empresas possuíam informações completas dos anos de 2010 e 2013, condição importante para a análise.

Os índices financeiros são considerados dados quantitativos que foram analisados por meio de cálculos matemáticos e técnicas estatísticas. Devido a estas características, inicialmente foi feita a comparação de médias para o grau de alavancagem, variável dependente, constituindo-se um teste paramétrico de duas amostras independentes. Este teste buscou demonstrar se elas possuem diferenças significante em termos estatísticos. Portanto, foi utilizado o teste 2-Sample $t$ para o conhecimento se existem diferenças entre a estrutura de capital dos dois grupos de empresas estudadas.

O mesmo teste estatístico verificou a diferença entre os atributos determinantes da governança corporativa, tamanho, rentabilidade e estrutura de propriedade, das empresas estudadas, Segmento Tradicional e Novo Mercado, nos anos de 2010 e 2013.

Na segunda etapa de testes estatísticos, o grau de alavancagem, variável escolhida para representar a estrutura de capital, dos dois segmentos de empresas presentes neste estudo, listagem tradicional e Novo Mercado, foram regredidos em função das variáveis independentes, o tamanho, a rentabilidade e a estrutura de propriedade.

Neste trabalho foram utilizadas regressões lineares múltiplas para verificar a relação entre o grau de alavancagem e os seus determinantes. Segundo Gujarati e Porter (2011), o modelo de regressão múltipla utiliza no mínimo três variáveis, a variável dependente $\mathrm{Y}$, ou regressando, e duas ou mais variáveis explanatórias ou regressores, conhecidas como $\mathrm{X}$. $\mathrm{O}$ objetivo é utilizar as variáveis independentes para prever o valor da variável dependente selecionada pelo pesquisador e o seu peso denota a sua contribuição relativa para a previsão 
geral. Os dados deverão ser métricos e é necessária uma definição clara de qual é variável dependente e quais são as independentes. (Hair et al, 2009).

\subsection{Escolha das variáveis da pesquisa}

\subsubsection{Variável Dependente, Variáveis Independentes e Hipóteses}

A variável dependente é aquela que é explicada por alguns atributos, ou variáveis dentro do escopo do trabalho. A variável dependente é aquela que aparece ao lado esquerdo do sinal de igualdade, e também é conhecida como variável endógena ou explicada. (Gujarati e Porter, 2011).

Neste trabalho a variável dependente é a estrutura de capital, representada pelo grau de alavancagem. Esta escolha foi baseada no trabalho desenvolvido por Silveira, Perobelli e Barros (2008), que tratou dos determinantes da estrutura de capital das empresas, incluídos alguns atributos, dentre eles a governança corporativa.

O Grau de Alavancagem pode ser determinado através da seguinte equação:

$$
\text { eq. } 1 \text { - - - O Grau de Alavancage } \mathrm{m}=\frac{\text { Dívida Financeira Total }}{\text { AtivoTotal }} \times 100
$$

O Grau de Alavancagem representa, segundo Silveira, Perobelli e Barros (2008), a dívida financeira total composta por empréstimos e financiamentos de curto e longo prazo, em moeda nacional e estrangeira, sobre o ativo total da empresa ao final do exercício.

A variável dependente foi utilizada para a realização de um teste que objetivou conhecer se o Grau de Alavancagem apresenta diferença estatisticamente significativa entre os dois segmentos de empresas analisadas: empresas do segmento tradicional da BM\&F Bovespa e as empresas do Novo Mercado.

A partir da escolha dos métodos, definem-se as seguintes hipóteses para este estudo. A hipótese nula, tratada como Ho, é a de que não existe diferença estatisticamente significativa entre os dois segmentos de empresas analisadas. X1 representa as empresas do segmento tradicional da BM\&F Bovespa e X2 são as empresas do Novo Mercado. 
A hipótese nula Ho é:

$$
\mathrm{Ho}=\mathrm{X} 1-\mathrm{X} 2=0
$$

A hipótese alternativa a Ho no trabalho, identificada como H1, é que as empresas do segmento do Novo Mercado possuem estrutura de capital, representada pelo Grau de Alavancagem, estatisticamente diferente de empresas da listagem tradicional da Bolsa de Valores.

A hipótese alternativa $\mathrm{H} 1$ é:

$$
\mathrm{H} 1=\mathrm{X} 1-\mathrm{X} 2 \neq 0
$$

Portanto:

Ho,1: não existe diferença estatística entre as médias de alavancagem financeira de X1 e X2

\section{Versus,}

\section{H1: existe diferença estatística entre as médias de alavancagem financeira de X1} e X2

Com a ocorrência da hipótese H1, comprova-se a existência de diferença estatística significante entre as empresas do Novo Mercado e do Segmento Tradicional no índice de estrutura de capital estudado.

O nível de significância alfa utilizado para analisar a validade dos resultados encontrados e o seu poder para explicar as relações estabelecidas através das hipóteses apresentadas foi de de 5\% (p_valor $=5 \%$ no teste bi-caudal) e, portanto, o intervalo de confiança de $95 \%$.

A condições para aceite da hipótese nula:

Se p_valor $<0,05$ rejeita-se Ho

A hipótese nula será aceita se:

Se $\mathrm{p} \_$valor $\geq 0,05$ não se rejeita Ho 
Esta mesma estrutura do teste apresentada foi também utilizada para a comparação dos atributos determinantes da estrutura de capital em 2010 e 2013. Os atributos representam variáveis independentes. A variável independente, de acordo com Gujarati e Porter (2011) é aquele que aparece do lado direito da equação de regressão, e é também conhecida como variável explanatória.

Neste estudo, os atributos para explicar a estrutura de capital são o tamanho da empresa, a rentabilidade e a estrutura de propriedade. Esta opção se deve aos trabalhos anteriores de determinantes da estrutura de capital desenvolvidos por Silveira, Perobelli e Barros (2008) e também Perobelli e Famá (2002) que utilizaram estes atributos.

Portanto, foram utilizadas as seguintes hipóteses:

\section{H2: existe diferença estatística entre as médias de tamanho de X1 e X2}

H3: existe diferença estatística entre as médias de rentabilidade de X1 e X2

H4: existe diferença estatística entre as médias de estrutura de propriedade de X1 e X2

Os resultados dos testes de significância, destas quatro variáveis, representam a primeira parte do trabalho, que buscou identificar se as empresas do segmento tradicional e empresas do Novo Mercado apresentaram diferenças entre si.

\subsubsection{Variáveis independentes e hipóteses}

A segunda etapa de testes estatísticos para o atendimento dos objetivos desta pesquisa foi desenvolvida com a utilização de equações de regressão linear múltipla com o objetivo de conhecer a influência das variáveis independentes na determinação da estrutura de capital.

A seguir, apresenta-se as variáveis independentes, suas justificativas e as suas respectivas hipóteses.

1. Tamanho da empresa. A utilização desse atributo como variável independente se justifica pela presença em trabalhos anteriores de determinantes da estrutura de capital, como Titman e Wessels (1998), Perobelli e Famá (2002), Silveira, Perobelli e Barros (2008). Nestes 
estudos anteriores, foram identificadas uma relação estatística significante da estrutura de capital com o tamanho das empresas.

\section{H5: Empresas maiores possuem maior grau de alavancagem}

O tamanho é um atributo utilizado para explicar a relação com o endividamento das empresas. Existem conclusões diversas sobre este atributo, mas a predominância é que existe uma relação positiva. Quanto maior o tamanho da empresa, maior o seu grau de endividamento. Segundo Silveira, Perobelli e Barros (2008), o tamanho será medido através do LN (logaritmo natural) do AT (Ativo Total).

2. Rentabilidade. A escolha deste atributo se justifica por ter sido utilizado em trabalhos anteriores da determinação da estrutura de capital, como Myers (1984), Myers e Majluf (1984), Titman e Wessels (1998), Perobelli e Famá (2002). Foi identificado nestes estudos anteriores, uma relação entre a rentabilidade e a estrutura de capital das empresas.

\section{H6: Empresas com maior rentabilidade possuem um menor grau de alavancagem}

\section{financeira.}

A rentabilidade demonstra a eficiência da empresa em produzir retorno econômico. É um atributo negativamente relacionado com o grau de endividamento, empresas com maior rentabilidade tendem a apresentar menor nível de endividamento. A rentabilidade será medida por meio da variável independente RPL (Retorno sobre Patrimônio Líquido, lucro líquido sobre patrimônio líquido) (Silveira, Perobelli e Barros, 2008).

3. Estrutura de Propriedade. Os autores Procianoy e Schnorrenberger (2004), Silveira, Perobelli e Barros (2008) utilizaram indicadores de estrutura de propriedade em estudos de determinantes de estrutura de capital, procurando estabelecer a relação existente entre o grau de concentração acionária das companhias e a formação da estrutura de capital.

H7: Empresas com estrutura de propriedade mais concentrada possuem maior grau de alavancagem financeira. 
A Estrutura de Propriedade é o último atributo escolhido para este trabalho como determinante da estrutura de capital. A suposição é que empresas com estrutura de propriedade mais concentrada, menos pulverizadas, em ambientes de assimetria de informação, busquem com maior intensidade a utilização de capitais de terceiros, representado por dívidas de curto e longo prazo (Black, 2001; Silveira, 2004; Silveira, Perobelli e Barros, 2008)

\section{ANALISE DE RESULTADOS}

A motivação para esta pesquisa residiu na possibilidade de a adoção da governança corporativa influenciar a estratégia empresarial, em especial a obtenção de recursos externos para alavancar os investimentos e o crescimento das organizações.

Este trabalho teve como objetivo geral identificar se as empresas pertencentes ao Novo Mercado, segmento das bolsas de valores brasileiras que adota regras diferenciadas para boas práticas de governança corporativa, apresentam alterações significativas em sua estrutura de capital e atributos, com relação às empresas do segmento tradicional da BM\&F Bovespa.

Para atender a esse objetivo foram realizados testes estatísticos de significância com o propósito de identificar diferenças, porventura existentes, entre os dois grupos de empresas, para os anos de 2010 e 2013. O resultado dos testes não indicou diferenças na estrutura de capital, representada pela alavancagem financeira, para os anos de 2010 e 2013 (Hipótese Ho1). No entanto, os atributos determinantes da estrutura de capital escolhidos para este estudo, apresentaram diferenças entre os dois grupos de empresas pesquisadas, podendo evidenciar características dos dois grupos de empresas estudadas (Hipóteses H2, H3 e H4).

Em primeiro lugar, os testes demonstraram que o tamanho das empresas do Novo Mercado foi considerado superior as empresas do segmento tradicional para 2010 e 2013, demonstrando que as organizações de maior porte, representado pelo ativo total, são mais propensas a adoção da governança corporativa em patamares mais elevados, com maior número de exigências para garantir os direitos dos envolvidos. (Hipótese H2). Este fato poderia ser justificado porque organizações maiores teriam um maior custo de agência e conflitos decorrentes da sua gestão com os diversos tipos de acionistas, motivando a adoção de boas práticas de governança corporativa para mitiga-los. A variável tamanho das empresas, ao incluí-la na análise de regressão linear múltipla, não se mostrou significativa para explicar a variação da estrutura de capital das empresas pesquisadas no ano de 2010 (Hipótese H5) 
A rentabilidade das empresas, medida pela proporção do lucro líquido versus patrimônio líquido das empresas, foi uma outra variável presente neste estudo para explicar a formação da estrutura de capital das empresas. A média de rentabilidade das empresas do Novo Mercado apresentou-se como superior as empresas do segmento tradicional, representando um indicador importante da eficiência da gestão das empresas com boas práticas de governança corporativa para criar retorno do investimento dos seus acionistas. (Hipótese H3). A governança corporativa com o enfoque em finanças, como Jensen e Meckling (1976), e em estudos no Brasil como Saito e Silveira (2008), Silveira, Perobelli e Barros (2008), tem como principal objetivo a satisfação obter a satisfação dos acionistas por meio do retorno do capital investido nas operações das empresas.

Nas equações de regressão propostas para este trabalho, não se demonstrou que a rentabilidade tem influência para a determinação da estrutura de capital das empresas, ou seja, que as empresas mais rentáveis são aquelas que utilizam em menor intensidade o capital de terceiros para a formação de suas fontes de financiamento. (Hipótese H6). Decorrente dos resultados deste estudo, pode-se pressupor que as empresas com governança corporativa são em média mais rentáveis e utilizarão com maior intensidade a captação de recursos financeiros por meio da oferta de ações no mercado de capitais.

A estrutura de propriedade foi outro atributo considerado neste trabalho para a determinação da estrutura de capital das empresas brasileiras. Foi considerado o grau de concentração da propriedade, por meio da posse das ações do maior acionista da organização. O teste 2 sample $t$, destinado a comparar as médias de estrutura de propriedade dos dois segmentos de empresas, demonstrou que as empresas do Novo Mercado, que adotam boas práticas de governança corporativa, possuem menor concentração de propriedade, sendo empresas que contam com maior pulverização de seu capital, atraindo um maior número de interessados em obterem a posse de seus papéis no mercado financeiro de capitais. (Hipótese H4). Esta representa mais uma evidência da maior utilização do capital obtido por meio das ações para as empresas do segmento do Novo Mercado, representando a principal estratégia de financiamento destas organizações. Nas equações de regressão, não foi possível estabelecer uma relação entre a estrutura de propriedade com a estrutura de capital das empresas pesquisadas. (Hipótese H7). No entanto, o trabalho pode demonstrar a permanência de estruturas de propriedade concentradas no Brasil, conforme constatado em trabalho anterior de Leal e Valadares (2002). 


\section{CONSIDERAÇÕES FINAIS}

O principal objetivo deste trabalho foi verificar se existem diferenças significativas na estrutura de capital entre as empresas pertencentes ao Novo Mercado e as empresas do segmento tradicional da BM\&F Bovespa.

Inicialmente pretendeu-se analisar as empresas dos dois segmentos para o período 2008 a 2013. No entanto, devido à crise internacional de 2008 optou-se por fazer este estudo excluindo também o ano imediatamente subsequente, de 2009, por entender que também nesse ano os negócios poderiam estar contaminados com a crise.

Optou-se neste trabalho por efetuar, ao invés de uma análise longitudinal, uma análise de dados do tipo corte transversal ou cross section, no qual buscou interpretar os períodos específicos, 2010 e 2013. A escolha destes dois anos ocorreu por se tratar de período recente e por não se ter conhecimento de pesquisa que tenha investigado os atributos que influenciam a estrutura de capital corporativa no Brasil nesses anos. Neste trabalho foram aplicados o teste 2 Sample $t$ e regressão linear múltipla e utilizadas regressões múltiplas para verificar a relação entre o grau de alavancagem e os seus determinantes.

A análise de resultados do trabalho demonstrou a presença de diferenças significativas entre os atributos determinantes da estrutura de capital das empresas analisadas, Novo Mercado e empresas tradicionais, de acordo com que foi proposto pelas hipóteses $\mathrm{H} 2, \mathrm{H} 3 \mathrm{e}$ H4.

As empresas com boas práticas de governança corporativa, presentes no Novo Mercado, conforme os resultados obtidos são empresas de maior porte (Hipótese H2), rentabilidade superior (Hipótese H3) e menor concentração de propriedade (Hipótese H4).

Estes aspectos evidenciam a influência positiva das boas práticas de governança corporativa nas variáveis desta pesquisa (tamanho, rentabilidade e estrutura de propriedade), favorecendo um melhor desempenho financeiro. Esta afirmativa se justifica por meio dos seguintes argumentos: companhias de maior porte atraem maior volume de recursos para financiamento de suas atividades, as mais rentáveis contam com fonte interna de financiamento provida pelo lucro apurado em suas próprias operações e a concentração de propriedade menor demonstra maior dispersão do capital e capacidade de se financiar no mercado acionário brasileiro.

Os determinantes para a formação da estrutura de capital das empresas contemplados neste estudo: tamanho (Hipótese H5), rentabilidade (Hipótese H6) e estrutura de propriedade 
(Hipótese H7), utilizados nas equações de regressão linear múltipla, apresentaram os resultados do coeficiente $\mathrm{R} 2$ de $12,12 \%$ e $11,11 \%$, respectivamente em 2010 e 2013, de acordo com o quadro 1 . O coeficiente R2 demonstra a capacidade da equação da regressão linear múltipla, por meio das variáveis independentes tamanho, rentabilidade e estrutura de propriedade, de explicar as variações ocorridas na variável dependente, grau de alavancagem financeira, em 2010 e 2013.

\begin{tabular}{|c|c|c|}
\hline Hipóteses do & Período do Teste & \multicolumn{1}{c|}{$\begin{array}{c}\text { Coeficiente R2 da } \\
\text { Equação de Regressão } \\
\text { Linear Múltipla }\end{array}$} \\
\hline H5, H6 e H7 & 2010 & $12,12 \%$ \\
\hline H5, H6 e H7 & 2013 & $11,11 \%$ \\
\hline
\end{tabular}

Quadro 1: Hipóteses do Trabalho e o Coeficiente R2

Seria desejável em trabalhos futuros, para aumentar o resultado do indicador R2 incorporar e analisar maior número de variáveis que poderiam influenciar a estrutura de capital, como por exemplo, a existência de garantias em ativos, incentivos tributários, crescimento das empresas, singularidade do setor, classificação industrial, volatilidade, conforme sugerido por Titman e Wessels (1998). Contudo há de se registrar que a parcimônia no aumento de variáveis explicativas busca conter uma multicolinearidade excessiva (Gujarati e Porter, 2011). 


\section{REFERÊNCIAS}

ALCHIAN, A. DEMSETZ, H. Production, information costs and economic organization. American Economic Review, 1972. v. 62, p.777-795.

ALVES, L. Governança e Cidadania Empresarial. Revista de Administração de Empresas, out-dez 2001. v. 41, no 4, p.78-86.

ANDRADE, A; ROSSETI, J.P. Governança Corporativa. São Paulo: Editora Atlas, 2012. ASSAF NETO, A. Finanças Corporativas e Valor. São Paulo: Editora Atlas, 2010.

ASSAF NETO, A. Mercado Financeiro. São Paulo: Editora Atlas, 2012.

BERLE, A. MEANS, G. The Modern Corporation and Private Property. New Brunswick and London: Transactions Publishers, 1932.

BLACK, B. Strengthening Brazil's securities markets. Journal of Commercial, Economic and Financial Law, Stanford Law School, Working Paper 205, 2001.

BMF\&Bovespa. Disponível em <http://www.bmfbovespa.com.br/cias-listadas/empresaslistadas/BuscaEmpresaListada.aspx?idioma=pt-br> Acesso em 15 fev. 2015.

COASE, R.H. The Nature of the Firm. Economica, 1937. v. 4, p.386-405.

GUJARATI, D. N; PORTER, D.C. Econometria Básica. Porto Alegre: AMGH Editora, 2011.

HAIR ET AL. Análise Multivariada de Dados. Porto Alegre: Bookman, 2009.

HARRIS, M. RAVIV, A. The Theory of Capital Structure. Journal of Finance, 1991. v. 46, p. 297-355.

JENSEN M. C. E MECKLING, W. H. Theory of the firm: managerial behavior, agency costs, and ownership structure. Journal of Financial Economics, oct. 1976. v. 3, n.4, p. 60305 .

LA PORTA, R ET. AL. Law and Finance. Journal of Political Economy, 1998. v. 106, p. 1113-1155.

LEAL, R; SILVA, A. VALADARES, S. Estrutura de Controle das Companhias de Capital Aberto. Curitiba: RAC, jan-abr. 2002. v. 6, n.1.

MYERS, S. C. The capital structure puzzle. The Journal of Finance, jul. 1984. v. 39, n. 3, p. 575-92.

MYERS, S. C. E MAJLUF, N. S. Corporate financing and Investment decisions when firms have information that investors do not have. Journal of Financial Economics, jun. 1984 v. 13, n. 2, p. 187-222. 
MYERS, S. (2002) Financing of Corporations. Amsterdam: Elsevier. Handbook of the economics of finance. 2002. vol. 1, p. 215-253.

MOdiGliani, F.; MILleR, M. The Cost of Capital, Corporation Finance and the Theory of Investment. The American Economic Review, jun. 1958. vol. XLVIII, n ${ }^{\circ} 3$.

PEIXOTO, F. Governança Corporativa, Desempenho, Valor e Risco: Estudos das Mudanças em Momento de Crise. 2012. Dissertação (Doutorado) - UFMG, Belo Horizonte. PEROBELLI, F. FAMA, R. Determinantes da estrutura de capital: aplicação a empresas de capital aberto brasileiras. São Paulo: R. Adm, jul.-set. 2002. v.37, n.3, p.33-46.

PROCIANOY, J. SCHONORRENBERGER, A. A influência da estrutura de controle nas decisões de estrutura de capital das companhias brasileiras. Rio de Janeiro: Revista Brasileira de Economia, 2004. v. 58 (1), p. 122-146.

SAITO, R.; SILVEIRA, A. Governança Corporativa: Custos de Agência e Estrutura de Propriedade. São Paulo: Revista de Administração de Empresas, abr-jun 2008. v. 48, n.2.

SILVEIRA, A. D. M. Governança Corporativa e estrutura de propriedade: determinantes e a relação com o desempenho das empresas no Brasil. 2004. Dissertação (Doutorado) - Faculdade de Economia, Administração e Contabilidade, Universidade de São Paulo, São Paulo.

SILVEIRA, A D M; PEROBELLI, F F C, BARROS, L A B C. Governança Corporativa e os Determinantes da Estrutura de Capital: Evidências Empíricas no Brasil. Curitiba: RAC, jul-set. 2008. v. 12, n.3, p.763-788.

TITMAN, S. WESSELS, R. The determinants of Capital Structure Choice. The Journal of Finance, mar 1998. 43 (1), 1-19. 